\title{
UK stance on adult GH replacement: the economist vs the endocrinologist
}

\author{
S M Shalet \\ Department of Endocrinology, Christie Hospital NHS Trust, Wilmslow Road, Manchester M2O 4BX, UK \\ (Correspondence should be addressed to S M Shalet; Email: stephen.m.shalet@manchester.ac.uk)
}

\begin{abstract}
In the UK, through the use of a forced economic model, endocrinologists are in the curious position of offering GH replacement to some patients with severe GH deficiency (GHD) but withholding it from other patients with even more severe GHD. This approach is counter-intuitive to endocrine practice in treating endocrine deficiency states. For all other endocrine deficiencies, one would opt for treating those with the most severe biochemical evidence of deficiency first. If this endocrine approach was applied to adult $\mathrm{GH}$ replacement in an era of rationing, one would start with the GHD patients with a pathologically low IGF1 level. Given that the prevalence of subnormal IGF1 levels in a GHD population is age-dependent, this would result in GH replacement being offered to more young adult onset (AO) GHD and childhood onset GHD adults, and less often to middle-aged and elderly AO GHD adults. This in itself has the added advantage that the skeletal benefits appear more real in the former cohort of patients.
\end{abstract}

European Journal of Endocrinology 169 R81-R87

\section{Introduction}

In adults beneficial effects of growth hormone $(\mathrm{GH})$ replacement on a variety of biological endpoints were first convincingly shown in $1989(1,2)$. These two pioneer studies assessed the effects of GH replacement in adults with documented hypothalamic-pituitary disease and GH deficiency (GHD); the studies $(1,2)$ were double-blind, placebo-controlled, and of 4-6 months' duration. Positive effects, potentially beneficial and attributable to $\mathrm{GH}$, were seen in body composition, consisting of increased lean body mass (LBM) and reduced fat mass (FM), exercise capacity, glomerular filtration rate and renal plasma flow, cholesterol and insulin-like growth factor 1 (IGF1) status. A further endpoint, studied but published separately (3), was quality of life $(\mathrm{QoL})$, which was measured using generic estimates (Nottingham Health Profile, Psychological General Well-being) and was significantly impaired at baseline in GHD adults compared with the background normal population. However, after 6 months of GH therapy QoL had improved significantly compared with baseline values and the placebo-treated group.

The scene was set for therapeutic advance. No longer could it be stated that GH had no function in adult life. Subsequently a series of predominantly epidemiologically based studies explored the key disadvantages to be expected in populations of adult GHD patients if left untreated for many years. Thus epidemiological and radiological studies $(4,5,6)$ concluded that hypopituitary adults, on full endocrine replacement with the exception of GH, had an approximately threefold increase in fracture rate.

\section{Author profile}

Professor Stephen Shalet is an Honorary Consultant Endocrinologist at the Christie Hospital, Manchester and Emeritus Professor of Endocrinology at the University of Manchester, UK. Previous positions include Chairman of the Strategic Planning Committee of the European Society of Pediatric Endocrinology, Co-Editor of the first edition of the Oxford Textbook of Endocrinology and a member of the Council of the Society for Endocrinology.

Professor Shalet has extensive research interests in the late endocrine effects following treatment of cancer, pituitary disorders and in particular abnormalities of growth hormone (GH) secretion. He is the author/co-author of over 500 articles and more than 200 of these are related to clinical disorders of the GH-IGF-1 axis and/or therapeutic use of GH therapy.

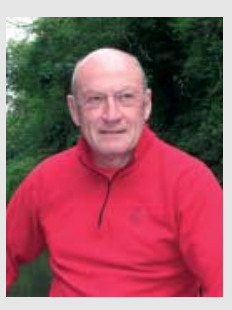


Unsurprisingly there was an early focus on mortality in cohorts of patients with hypopituitarism on full endocrine replacement except for GH. Six large early epidemiological studies $(7,8,9,10,11,12)$ had certain features in common; they excluded patients treated for acromegaly or Cushing's disease, the median patient age ranged from 46 to 52 years, the duration of followup, i.e. minimum length of time a patient was $\mathrm{GH}$ deficient, ranged between 10 and 13 years, and there was a slight preponderance of males $(51-62 \%)$ in the studied cohorts. Overall, these studies, despite not being in complete agreement, concluded that the standardised mortality ratio (SMR) was increased twofold in these hypopituitary adults, and the main contributor to the increased SMR was vascular disease. The increased vascular mortality was more predominant in females than in males but whether or not the increased vascular mortality reflected cardiovascular rather than cerebrovascular disease remained unsettled.

\section{Definition of GHD}

GHD, like all endocrine deficiency states, exists as a continuum from severe to mild (13) merging seamlessly into normality. The key biochemical study defining the GH status threshold below which GH therapy might be offered to a patient was published in 1994 by Hoffman et al. (14). These authors (14) compared four methods of assessing GH status in middle-aged adults with hypopituitarism and age-matched controls. The four estimates consisted of the peak GH response to an insulin tolerance test (ITT), 24-h GH profile, basal IGF1 and IGFBP3; the greatest discrimination was achieved with the peak GH response to an ITT, whereby no patient achieved a peak $\mathrm{GH}$ response $>3 \mathrm{ng} / \mathrm{ml}$ and no control a response $<5 \mathrm{ng} / \mathrm{ml}$. Throughout the article Hoffman et al. (14) referred only to GHD; it was only later that their biochemical threshold of a peak $\mathrm{GH}$ response of $3 \mathrm{ng} / \mathrm{ml}$ was adopted by formal guidelines (15), and quite casually used to define severe GHD as opposed to the broader term GHD which encompasses all degrees of GHD. Pursuing that point further, it is important to appreciate that the vast majority of hypopituitary patients, studied by Hoffman et al. (14), had multiple pituitary hormone deficiencies (MPHD). This observation leads to the understanding that the 'gold standard' for diagnosing severe GHD is not a particular provocation test threshold response but rather the presence of MPHD. Confirmatory data published in the same year (1994) by Toogood et al. (16), with a much larger cohort of patients, supported the belief that, even if arbitrarily defined, a peak GH threshold of $3 \mathrm{ng} / \mathrm{ml}$ to an ITT was a reasonable starting point for deciding which patients qualified for the advancing use of GH replacement in adults.

\section{Benefits of GH replacement}

Gradually over time and with an expanding literature, certain key benefits, potential and/or real, were attributed to GH replacement in adults with severe GHD. These consisted of an improvement in body composition, improvement in QoL, reduction in the increased SMR and fracture rate reported in hypopituitary adults or improvement in the surrogate markers for these unwanted adverse outcomes.

\section{Body composition}

In almost any new 6-month or 1-year trial of a new method of administering GH, i.e. depot formulations, body composition change is usually the primary endpoint chosen, reflecting, at least in part, the consistency of the responses.

The advantage of the increased LBM and reduced FM appeal because of the associated increase in exercise capacity, potential reduction in insulin resistance, and possible decrease in the elevated SMR reported in the untreated state. Long-term follow-up studies (17) show that the gain in LBM is maintained for at least 10 years of GH replacement both in men and women, although the time course of change differs between the genders. In men, most of the FM lost in the first year of GH replacement does not recur over the next 9 years; whereas in women, the FM that is lost within the first year is regained during the subsequent 2 years of GH replacement, after which FM status is unchanged up until 10 years of GH replacement therapy.

\section{Quality of life}

Approximately $35-40 \%$ of patients with severe GHD perceive their QoL to be severely impaired (18). Significant benefit in QoL is seen within the first few months of GH replacement in those in whom QoL is impaired at baseline (19). The data supporting these observations are gathered from patient interviews, and the use of generic and disease-generated questionnaires. The benefit in QoL is maintained for at least $6-10$ years and the evidence is derived from audit of practice single centre studies $(20,21)$ and pharmaceutical database registries (22).

As well as the typically early QoL response to GH replacement, the greatest gain in QoL is seen in those patients with the worst QoL at baseline; both attributes are attractive to the clinician and the patient. Curiously and unexplained, severe impairment of QoL is more frequently seen in adult patients with adult onset (AO) GHD compared with patients with childhood onset (CO) GHD (23).

There are additional, even more critical, gaps in our understanding of the impact of GH on QoL. There has been no conclusive demonstration of any correlation 
between QoL at baseline or QoL response to $\mathrm{GH}$ replacement and baseline peak $\mathrm{GH}$ response to a stimulation test or IGF1 status. However, the first glimmer of a relationship was hinted at recently when Varewijck et al. (24) observed a weak correlation $(r=0.28)$ between QoL status and IGF1 bioactivity after 12 months' GH replacement.

The mechanism underlying the improvement in QoL also remains speculative. Various possibilities have been put forward: a direct CNS effect or an indirect effect via changes in cardiac function, body composition or hydration status. Unfortunately there is no study correlating a change in any of the speculative mechanisms with a change in QoL. Finally, no randomised, placebo-controlled study has ever been carried out in the subset of patients with severe impairment of QoL.

\section{Vascular mortality}

In the epidemiological studies which revealed an increased SMR in patients with hypopituitarism on full endocrine replacement with the exception of GH, it was tempting to speculate that the increased mortality was a direct consequence of untreated GHD. The plausibility of the latter suggestion was compromised by the heterogeneity of the cohorts of patients studied $(7,8$, $9,10,11,12)$; there were: i) differences in the primary pituitary pathology, i.e. craniopharyngioma vs pituitary adenoma; ii) variation in the number of patients that received pituitary radiotherapy, known itself to be associated with cerebrovascular disease; and iii) undoubtedly differences in the degree of hypopituitarism and manner of endocrine replacement amongst the cohorts of patients studied.

Furthermore, the epidemiological study cohorts had been $\mathrm{GH}$ deficient for at least 10 years $(7,8,9,10,11,12)$ and clearly a 10-year randomised, placebo-controlled trial would never take place. Thus an alternative strategy has been employed in which the mortality data available in GH deficient patients on GH replacement have been compared with that of the background population of the country from which the patients were studied. Van Bunderen et al. (25) reviewed mortality in 2229 GHD adults treated with $\mathrm{GH}$ for a median time of 5.7 years; $\mathrm{GH}$ deficient men receiving $\mathrm{GH}$ had a mortality not different from the background population, whereas in women, after exclusion of high-risk patients, mortality was not different from the background population except for cardiovascular disease.

Svensson et al. (26) used a similar comparative approach with 229 Swedish GH deficient patients who had received $\mathrm{GH}$ replacement for a mean time of 5 years and found no difference in overall mortality from that of the background population. More recently, Burman et al. (27) investigated all-cause and cause-specific mortality in 1286 Swedish patients with hypopituitarism prospectively monitored in the KIMS registry database (1995-2009) and compared the data with that of the general population in the Swedish National Cause of Death Registry. In contrast to earlier studies, cardiovascular or cerebrovascular mortality did not significantly exceed that of the reference population. However, an excess mortality in the patient cohort was observed due to two important causes: hypocortisolism in response to acute stress and intercurrent illness; and secondly, increased risk of a de novo malignant brain tumour in patients who previously received radiotherapy.

However, in view of the multiple changes taking place in the overall management of patients with pituitary tumours and hypopituitarism since the early epidemiological studies, it cannot be assumed that the normalisation of cardiovascular and cerebrovascular mortality in this cohort of patients is necessarily attributable to $\mathrm{GH}$ replacement.

In the absence of unequivocal mortality evidence that $\mathrm{GH}$ replacement is beneficial, there is heavy reliance on changes in surrogate markers of vascular disease. Abnormalities in numerous vascular risk factors have been reported in untreated GH deficient adults; these include increased waist-to-hip ratio, dyslipidaemia, endothelial dysfunction, increased intima media thickness, increased fibrinogen, increased PAI-I, increased CRP, insulin resistance and hypertension.

The short-term effects of $\mathrm{GH}$ replacement on cardiovascular risk factors are known. A meta-analysis of placebo-controlled studies in $\mathrm{GH}$ deficient adults showed favourable effects of short-term (up to 1.5 years) $\mathrm{GH}$ replacement therapy on total cholesterol and HDLcholesterol levels, diastolic blood pressure (BP) and body composition but unfavourable effects on glucose and insulin levels (28). Claessen et al. (29) recently reported the effects of long-term GH therapy beyond 5 years on metabolic parameters. Total cholesterol and LDLcholesterol levels were lower, and HDL-cholesterol levels were significantly higher during long-term GH replacement compared with baseline. Both waist circumference and BMI were significantly higher after 10 years, as were fasting glucose levels. No significant changes were observed in triglycerides, waist-to-hip ratio and BP during follow-up (29).

In a subset of patients who had received 15 years of $\mathrm{GH}$ therapy, similar metabolic effects were found. The prevalence of metabolic syndrome was increased after 10 years both in comparison with baseline but also compared with normative age-matched Dutch data (29). Thus the exact net beneficial effect of GH replacement on overall cardiovascular risk remains unknown.

\section{Fractures}

In a single centre open-label study, Elbornsson et al. (30) studied the effects of 15 years of GH replacement on bone mineral content (BMC) and bone mineral density 
(BMD) measured by dual X-ray absorptiometry in 126 hypopituitary adults with a mean age of 49.4 years. There was a sustained increase in total body and lumbar spine BMC and BMD. In femur neck, BMC and BMD peaked at 7 years and then decreased towards baseline values. The authors suggest quite reasonably that this increase in bone mass and density is likely to reduce the fracture risk in GHD patients.

There are, however, a large number of confounding variables which may explain the early epidemiological reports of a two- to threefold increase in fracture rate in hypopituitary adults on full endocrine replacement other than $\mathrm{GH}$; these include adequacy and dosage of glucocorticoid replacement, sex steroid replacement and thyroxine replacement, visual impairment and increased falls and, of course, GHD.

Low bone mass is reported to be, and widely accepted as a characteristic of the adult GH deficient state. However, accumulating data suggest that BMD may not be reduced in the majority of individuals with GHD. Our own experience in $\mathrm{GH}$ deficient adults revealed BMD to be dependent on age, with low BMD being observed in the young patients but with patients over the age of 60 years demonstrating a mean BMD Z-score above that of the reference population (31); few patients over 30 years had a Z-score $<-2$ (31). Further volumetric bone studies revealed no morphometric abnormalities in AO GH deficient patients, whereas $\mathrm{CO} \mathrm{GH}$ deficient patients have marginally reduced cortical density but significantly reduced cortical bone as a result of reduced cortical thickness and bone size (32).

The bone abnormalities described in the adults with CO GHD are consistent with the studies of GH deficient post-pubertal patients (mean age 19 years) in whom the acquisition of peak bone mass is sub-optimal if they remain off $\mathrm{GH}$ replacement following treatment in childhood (33). It should be emphasised however that the most persuasive evidence that GH replacement significantly increases total BMC in this situation was obtained in severely GH deficient subjects defined by an IGF1 level below the first centile (33).

There have been attempts to determine whether the fracture incidence falls in $\mathrm{GH}$ deficient adults on $\mathrm{GH}$ replacement (34). In reality, however, the goal of determining the contribution of GH replacement, rather than the other confounding variables, in a patient cohort followed long enough over several decades is simply impossible to achieve.

\section{The UK attitude to adult GH replacement}

\section{Economist}

In 2003 the National Institute of Clinical Excellence (NICE) completed and published its evaluation of the appropriateness of GH replacement in GHD adults in the
UK. To be eligible for GH replacement, it needs to be demonstrated that patients have severe impairment of QoL, reflected by a reported score of at least 11 in the 'QoL Assessment of GHD in Adults' (QoL-AGHDA) questionnaire; this has a score range of $0-25$ with a higher score denoting poorer QoL. The guidance further stipulated that patients commenced on GH replacement should be re-assessed 9 months after the initiation of therapy (allowing for a dose titration period of 3 months followed by a 6 -month therapeutic trial period) and that GH therapy should be discontinued in those patients demonstrating a QoL improvement of less than seven points on the QoL-AGHDA score.

The initial assessment report commissioned by NICE confined itself to double-blind, placebo-controlled clinical studies; however, in clinical practice there has been a significant reduction in GH replacement dosage subsequent to the early controlled trials as current titration uses IGF1 generation rather than body weight. In addition, it was not possible to determine utility gain and cost per quality-adjusted life years (QALYs) from this initial assessment report and therefore a subsequent health economic cost-effectiveness analysis was undertaken by the Sheffield School of Health and Related Research (SCHARR). This analysis concluded that the long-term beneficial effects of $\mathrm{GH}$ on risk factors for fractures and cardiovascular disease had a minor impact on cost-effectiveness; the subsequent analysis was based solely on QoL improvement with GH therapy. To determine the latter, SCHARR used data from KIMS that included $\sim 80 \%$ of adult GH replaced patients in the UK at that time.

The Appraisal Committee concluded that a minimum improvement of at least seven points in the QoL-AGHDA score would be needed to achieve an acceptable level of cost-effectiveness. The guidance also indicated that a baseline QoL-AGHDA score of 11 or worse must be present in order for an individual patient to qualify for commencement of GH replacement. The latter ruling was based on data from KIMS indicating that an average improvement of seven points in QoL-AGHDA was only achieved in patients with a baseline QoLAGHDA score of 11 or worse.

The UK endocrine community argued strongly against the NICE economic argument, pointing out that it was inappropriate to take mean data for cost-effectiveness and to then derive stringent cut-offs for individual patients based on these mean data. It was further argued that the application of an entry hurdle of 11 points on QoL-AGHDA was incorrect when considering individual patient data, as such a baseline score is not a prerequisite for demonstrating an improvement of seven points. In the event, these points of appeal were rejected and the final guidance was published. In reaching this decision, NICE had moved from the usual situation of requiring a demonstration of cost-effectiveness in a treatment population to one in which each patient treated must demonstrate cost-effectiveness against the 
mean cost-effectiveness criterion - thereby presumably reducing the cost per QALY to below the level that had been considered cost-effective in the first place!

\section{Endocrine perspective}

The approach to $\mathrm{GH}$ replacement in adults in the UK clearly represented a form of health care rationing. By forcing the benefit gained in one symptom complex, QoL, into a health economic model, the guidelines for adult $\mathrm{GH}$ replacement could be inserted into therapeutic guidance for all treatments across all specialities of medicine with the appearance of a level playing field for all such decision making.

In the meantime, in many European countries and the USA, the overall impact on body composition, cardiovascular risk factors, predictors of skeletal health and QoL was considered sufficiently persuasive for $\mathrm{GH}$ replacement to be offered to severely GHD adults on holistic grounds.

It should not be thought however that the 'holistic' approach to adult $\mathrm{GH}$ replacement avoided rationing decisions. In the last 10 years published data have shown that adults with partial GHD (GH insufficiency) have abnormalities of body composition and cardiovascular risk factors but to a lesser degree than seen in adults with severe GHD (13). Notwithstanding the fact that the diagnosis of partial GHD in an individual patient may prove extremely difficult, there has been no clinical trial of GH replacement in such a patient cohort and no attempt based on holistic grounds to recommend GH replacement for partially GHD adults. Thus even when the therapeutic decision is based on holistic grounds, rationing insists that $\mathrm{GH}$ replacement be reserved for those adults with severe GHD despite the fact that the severity of the GHD is defined in a completely arbitrary manner.

The UK model of adult GH replacement based solely on QoL impairment throws up another conundrum. The conundrum is caused by the lack of any clear relationship between QoL and any biochemical marker of GH status. Thus in individuals with panhypopituitarism and failed $\mathrm{GH}$ responses to provocative testing, only those with sufficiently impaired QoL will be offered $\mathrm{GH}$ replacement. However, only $50 \%$ of middle-aged adults with panhypopituitarism have a subnormal IGF1 level; therefore, this means that endocrinologists are restricted to offering $\mathrm{GH}$ replacement to severely $\mathrm{GH}$ deficient adults with severely impaired QoL irrespective of IGF1 status, but withholding GH replacement from adults with severe GHD, a subnormal IGF1 level but a reported reasonable QoL.

In 2007, however, Brabant et al. (35) clearly showed that in adults with severe GHD, defined by their GH responses to provocative tests, there is a relationship between the peak GH response and IGF1 status; in other words, not surprisingly, those with subnormal IGF1 levels are more severely $\mathrm{GH}$ deficient than those with normal IGF1 levels.

Thus in the UK through the use of a forced economic model, endocrinologists are in the curious position of offering GH replacement to some patients with severe GHD but withholding it from other patients with even more severe GHD.

This approach is counter-intuitive to endocrine practice in treating endocrine deficiency states. For all other endocrine deficiencies, one would opt for treating those with the most severe biochemical evidence of deficiency first.

If this endocrine approach was applied to adult $\mathrm{GH}$ replacement in an era of rationing, one would start with the GHD patients with a pathologically low IGF1 level. Given that the prevalence of subnormal IGF1 levels in a GHD population is age-dependent, this would result in $\mathrm{GH}$ replacement being offered to more young AOGHD and COGHD adults, and less often to middle-aged and elderly AOGHD adults. This in itself has the added advantage that the skeletal benefits appear more real in the former cohort of patients.

A counter-argument to such an approach might be that the QoL indication is predictive of greater patient compliance with $\mathrm{GH}$ replacement than the holistic approach. Although there is no evidence to support this counter-argument, it is likely to be true.

However, with the advent of depot GH, which only requires an injection once weekly for replacement purposes, rather than the daily injection, the force of the counter-argument is weakened considerably.

\section{Declaration of interest}

The author has received numerous lecture fees, and, in the past, review support from growth hormone-producing pharmaceutical companies.

\section{Funding}

This review did not receive any specific grant from any funding agency in the public, commercial or not-for-profit sector.

\section{References}

1 Jorgensen JO, Pedersen SA, Thuesen L, Jorgensen J, Ingemann Hansen T, Skakkebaek NE \& Christiansen JS. Beneficial effects of growth hormone treatment in GH-deficient adults. Lancet $1989 \mathbf{1}$ 1221-1225. (doi:10.1016/S0140-6736(89)92328-3)

2 Salomon F, Cuneo RC, Hesp R \& Sonksen PH. The effects of treatment with recombinant human growth hormone on body composition and metabolism in adults with growth hormone deficiency. New England Journal of Medicine 1989321 1797-1803. (doi:10.1056/NEJM198912283212605)

3 McGauley GA, Cuneo RC, Salomon F \& Sonksen PH. Psychological well-being before and after growth hormone treatment in adults with growth hormone deficiency. Hormone Research 199033 (Suppl) 52-54. (doi:10.1159/000181584) 
4 Rosen T, Wilhelmsen L, Landin-Wilhelmsen K, Lappas G \& Bengtsson BA. Increased fracture frequency in adult patients with hypopituitarism and GH deficiency. European Journal of Endocrinology 1997137 240-245. (doi:10.1530/eje.0.1370240)

5 Wuster C. Fracture rates in patients with growth hormone deficiency. Hormone Research $2000 \mathbf{5 4}$ (Suppl 1) 31-35. (doi:10.1159/000053295)

6 Wuster C, Abs R, Bengtsson BA, Bennmarker H, FeldtRasmussen U, Hernberg-Stahl E, Monson JP, Westberg B \& Wilton P. The influence of growth hormone deficiency, growth hormone replacement therapy, and other aspects of hypopituitarism on fracture rate and bone mineral density. Journal of Bone and Mineral Research 200116 398-405. (doi:10.1359/jbmr. 2001.16.2.398)

7 Rosen T \& Bengtsson BA. Premature mortality due to cardiovascular disease in hypopituitarism. Lancet $1990336285-288$. (doi:10.1016/0140-6736(90)91812-0)

8 Bates AS, Van't Hoff W, Jones PJ \& Clayton RN. The effect of hypopituitarism on life expectancy. Journal of Clinical Endocrinology and Metabolism $1996 \mathbf{8 1}$ 1169-1172. (doi:10.1210/jc.81.3. 1169)

9 Bulow B, Hagmar L, Mikoczy Z, Nordstrom CH \& Erfurth EM. Increased cerebrovascular mortality in patients with hypopituitarism. Clinical Endocrinology 199746 75-81. (doi:10.1046/j. 1365-2265.1997.d01-1749.x)

10 Bates AS, Bullivant B, Sheppard MC \& Stewart PM. Life expectancy following surgery for pituitary tumours. Clinical Endocrinology 199950 315-319. (doi:10.1046/j.1365-2265. 1999.00650.x)

11 Nilsson B, Gustavasson-Kadaka E, Bengtsson BA \& Jonsson B. Pituitary adenomas in Sweden between 1958 and 1991: incidence, survival and mortality. Journal of Clinical Endocrinology and Metabolism 200085 1420-1425. (doi:10.1210/jc.85.4. 1420)

12 Tomlinson JW, Holden N, Hills RK, Wheatley K, Clayton RN, Bates AS, Sheppard MC \& Stewart PM. Association between premature mortality and hypopituitarism. West Midlands Prospective Hypopituitary Study Group. Lancet 2001357 425-431. (doi:10.1016/S0140-6736(00)04006-X)

13 Shalet SM. Partial growth hormone deficiency in adults; should we be looking for it? Clinical Endocrinology 201073 432-435.

14 Hoffman DM, Ngugen TV, O'Sullivan AJ, Baxter RC \& Ho KK. Diagnosis of growth hormone deficiency in adults. Lancet 1994 344 482-483. (doi:10.1016/S0140-6736(94)91821-X)

15 Growth Hormone Research Society. Consensus guidelines for the diagnosis and treatment of adults with growth hormone deficiency, summary statement of the Growth Hormone Research Society Workshop on Adult Growth Hormone Deficiency. Journal of Clinical Endocrinology and Metabolism $1998 \quad 83$ 379-381. (doi:10.1210/jc.83.2.379)

16 Toogood AA, Beardwell CG \& Shalet SM. The severity of growth hormone deficiency in adults with pituitary disease is related to the degree of hypopituitarism. Clinical Endocrinology $1994 \mathbf{4 1}$ 511-516. (doi:10.1111/j.1365-2265.1994.tb02583.x)

17 Gotherstrom G, Bengtsson BA, Bosaeus I, Johannsson G \& Svensson J. A 10-year prospective study of the metabolic effects of growth hormone replacement in adults. Journal of Clinical Endocrinology and Metabolism 200792 1442-1445. (doi:10.1210/jc.2006-1487)

18 Holmes SJ \& Shalet SM. Factors influencing the desire for long-term growth hormone replacement in adults. Clinical Endocrinology 199543 151-157. (doi:10.1111/j.1365-2265. 1995.tb01909.x)

19 Murray RD, Skillicorn CJ, Howell SJ, Lissett CA, Rahim A \& Shalet SM. Dose titration and patient selection increases the efficacy of GH replacement in GHD adults. Clinical Endocrinology 199950 749-757. (doi:10.1046/j.1365-2265.1999. 00722.x)

20 Gilchrist FJ, Murray RD \& Shalet SM. The effect of long-term untreated growth hormone deficiency (GHD) and 9 years of $\mathrm{GH}$ replacement on the quality of life of GH deficient adults. Clinical Endocrinology $2002 \quad \mathbf{5 7}$ 363-370. (doi:10.1046/j.1365-2265. 2002.01608.x)

21 Gibney J, Wallace JD, Spinks T, Schnorr L, Ranicar A, Cuneo RC, Lockhart S, Burnand KG, Salomon F, Sonksen PH et al. The effects of 10 years of recombinant human growth hormone in adult GH-deficient patients. Journal of Clinical Endocrinology and Metabolism 199984 2596-2602. (doi:10. $1210 /$ jc. 84.8.2596)

22 Koltowska-Haggstrom M, Mattsson AF \& Shalet SM. Assessment of quality of life in adult patients with GH deficiency: KIMS contribution to clinical practice and pharmacoeconomic evaluations. European Journal of Endocrinology 2009161 (Suppl 1) 51-64. (doi:10.1530/EJE-09-0266)

23 Murray RD, Skillicorn CJ, Howell SJ, Lissett CA, Rahim A, Smethurst LE \& Shalet SM. Influences on quality of life in GH deficient adults and their effect on response to treatment. Clinical Endocrinology 199951 565-573. (doi:10.1046/j.1365-2265. 1999.00838.x)

24 Varewijck AJ, Lamberts SW, Neggers SJ, Hofland LJ \& Janssen JA. IGF-I bioactivity might reflect different aspects of quality of life than total IGF-I in GH-deficient patients during GH treatment. Journal of Clinical Endocrinology and Metabolism 201398 761-768. (doi:10.1210/jc.2012-2901)

25 Van Bunderen CC, van Nieuwpoort C, Arwent LI, Heymans MW, Franken AA, Koppelschaar HP, van der Lely AJ \& Drent ML. Does growth hormone replacement therapy reduce mortality in adults with growth hormone deficiency? Data from the Dutch National Registry of growth hormone treatment in adults. Journal of Clinical Endocrinology and Metabolism 201196 3151-3159. (doi:10.1210/jc.2011-1215)

26 Svensson J, Bengtsson BA, Rosen T, Oden A \& Johannson G. Malignant disease and cardiovascular morbidity in hypopituitary adults with or without growth hormone replacement therapy. Journal of Clinical Endocrinology and Metabolism 200489 3306-3312. (doi:10.1210/jc.2003-031601)

27 Burman P, Mattsson AF, Johannsson G, Hoybe C, Holmer H, Dahlquist P, Berinder K, Engstrom BE, Ekman B, Erfurth EM et al. Deaths among adult patients with hypopituitarism: hypocortisolism during acute stress and de novo malignant brain tumours contribute to an increased mortality. Journal of Clinical Endocrinology and Metabolism 201398 1466-1475. (doi:10.1210/ jc. 2012-4059)

28 Maison P, Griffin S, Nicoue-Beglah M, Haddad N, Balkau B \& Chanson $\mathrm{P}$. Impact of $\mathrm{GH}$ treatment on cardiovascular risk factors in GH deficient adults: a meta-analysis of blinded randomised placebo-controlled trials. Journal of Clinical Endocrinology and Metabolism 200489 2192-2199. (doi:10.1210/jc. 2003-030840)

29 Claessen KM, Appelman-Dijkstra NM, Adopotie DM, Roelfsema F, Smit JW, Biermasz NR \& Pereira AM. Metabolic profile in growth hormone deficient adults after long-term recombinant human growth hormone therapy. Journal of Clinical Endocrinology and Metabolism 201398 352-361. (doi:10.1210/jc. 2012-2940)

30 Elbornsson M, Gotherstrom G, Bosaeus I, Bengtssen BA, Johannsson G \& Svensson J. Fifteen years of GH replacement increases bone mineral density in hypopituitary patients with adult-onset GH deficiency. European Journal of Endocrinology 2012 $166787-795$.

31 Murray RD, Columb B, Adams JE \& Shalet SM. Low bone mass is an infrequent feature of the adult growth hormone deficiency syndrome in middle-aged adults and the elderly. Journal of Clinical Endocrinology and Metabolism 200481 1124-1130. (doi:10.1210/jc.2003-030685)

32 Murray RD, Adams JE \& Shalet SM. A densitometric and morphometric analysis of the skeleton in adults with varying degrees of growth hormone deficiency. Journal of Clinical Endocrinology and Metabolism 200691 432-438. (doi:10.1210/ jc.2005-0897) 
33 Shalet SM, Shavrikova E, Cromer M, Child CJ, Keller E, Zapletalova J, Moshang T, Blum WF, Chipman JJ, Quigley CA et al. Effect of $\mathrm{GH}$ treatment on bone in postpubertal $\mathrm{GH}$ deficient patients: a 2 year randomised controlled dose-ranging study. Journal of Clinical Endocrinology and Metabolism $2003 \mathbf{8 8}$ 4124-4129. (doi:10.1210/jc.2003-030126)

34 Holmer H, Svensson J, Rylander L, Johannsson G, Rosen T, Bengtsson BA, Thoren M, Hoybe C, Degerblad M, Bramnert M et al. Fracture incidence in $\mathrm{GH}$-deficient patients on complete hormone replacement including GH. Journal of Bone and Mineral Research 200722 1842-1850. (doi:10.1359/jbmr.070811)
35 Brabant G, Krogh Rasmussen A, Biller B, Buchfelder M, FeldtRasmussen U, Forssmann K, Jonsson B, Koltowska-Haggstrom M, Maiter D, Saller B et al. Clinical implications of residual growth hormone response to provocative testing in adults with severe $\mathrm{GH}$ deficiency. Journal of Clinical Endocrinology and Metabolism 2007 92 2604-2609. (doi:10.1210/jc.2007-0153)

Received 17 May 2013

Accepted 29 July 2013 